\title{
Isolation and characterization of eight polymorphic microsatellites for the spotted spiny lobster, Panulirus guttatus
}

Nathan Truelove, Donald C Behringer, Mark J Butler IV, Richard F Preziosi

Microsatellite sequences were isolated from enriched genomic libraries of the spotted spiny lobster, Panulirus guttatus using 454 pyrosequencing. Twenty-nine previously developed polymerase chain reaction primer pairs of Panulirus argus microsatellite loci were also tested for cross-species amplification in Panulirus guttatus. In total, eight consistently amplifying, and polymorphic loci were characterized for 57 individuals collected in the Florida Keys and Bermuda. The number of alleles per locus ranged from 8 to 20 and observed heterozygosities ranged from 0.409 to 0.958 . Significant deviations from Hardy-Weinberg equilibrium were found in one locus from Florida and three loci from Bermuda. Quality control testing indicated that all loci were easy to score, highly polymorphic and showed no evidence of linkage disequilibrium. Null alleles were detected in three loci with moderate frequencies ranging from (20\% to $22 \%$ ). These eight microsatellites provide novel molecular markers for future conservation genetics research of $P$. guttatus. 


\section{Isolation and characterization of eight polymorphic microsatellites for the spotted spiny}

\section{2 lobster, Panulirus guttatus}

3 Nathan K. Truelove ${ }^{*}$, Donald Behringer $\mathrm{Jr}^{2}$, Mark Butler IV ${ }^{3}$, and Richard F. Preziosi ${ }^{1}$

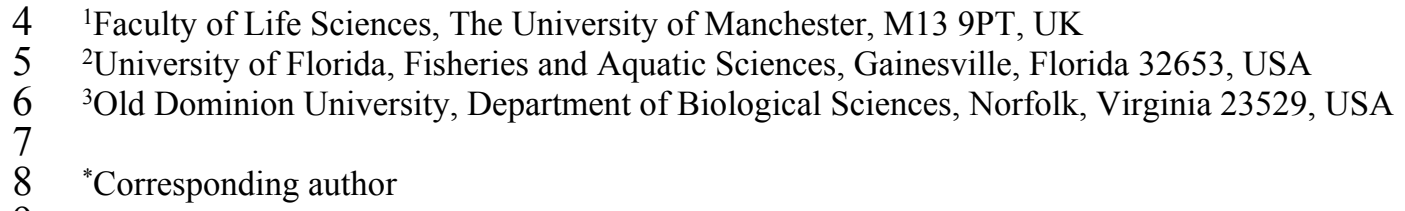

\section{Introduction}

11 The spotted spiny lobster Panulirus guttatus is a coral reef dwelling species that occurs

12 from Bermuda to Suriname and throughout the Caribbean Sea (Sharp, Hunt \& Lyons, 1997). $P$.

13 guttatus is believed to have a long pelagic larval duration and occupies the same coral reef

14 habitat throughout all of its benthic stages (Sharp et al., 1997). P. guttatus matures at a relatively

15 small size compared to other species of spiny lobster (females $32 \mathrm{~mm}$ carapace length (CL),

16 males 36-37 mm CL). Despite its small size fishing pressure has begun to increase due to

17 declining Panulirus argus fisheries in the Caribbean (Wynne \& Coté, 2007; Fanning, Mahon \&

18 McConney, 2011). Fishery regulations for P. guttatus are either extremely limited (e.g., Bermuda

19 and Martinique) or non-existent, and fisheries are emerging in the British West Indies and

20 several other Caribbean nations to satisfy the demand for luxury seafood (Acosta \& Robertson,

21 2003; Wynne \& Coté, 2007). Management is hindered by a lack of basic life history, ecology,

22 and population information - all of which would be facilitated by the development of species-

23 specific genetic tools.

This study aims to enable future genetic studies on $P$. guttatus by characterizing new microsatellites for the species. Whilst microsatellites have already been developed for several spiny lobster species from the genus Panulirus (Decapoda: Palinuridae) (Ben-Horin et al., 2009;

27 Kennington et al., 2010; Dao, Todd \& Jerry, 2013; Liu, Yang \& Liu, 2013), only microsatellites 
28 for P. argus (Diniz et al., 2004; 2005; Tringali, Seyoum \& Schmitt, 2008) were only tested for

29 cross-species amplification since the success rate of amplification in more distantly related

30 congeners (Ptacek et al., 2001) is generally low (Ben-Horin et al., 2009). These microsatellite

31 primers will allow researchers to identify genetically unique subpopulations, determine levels of

32 genetic diversity, and measure levels of genetic connectivity among subpopulations of $P$.

33 guttatus.

34 Methods

The authors collected DNA samples from $P$. guttatus, completed DNA extractions, and tested validated microsatellite loci for polymorphism. Genoscreen, France (www.genoscreen.fr) tested $P$. guttatus DNA for quality and quantity, developed microsatellite libraries, performed 454 pyrosequencing, used bioinformatics software to identify potentially amplifiable microsatellite loci, and validated potentially amplifiable loci. Leg muscle tissue was collected from 24 individuals from Long Key Florida and 33 individuals from North Rock Bermuda. Total genomic DNA was isolated with the Wizard SV-96 Genomic DNA extraction kit (Promega).

Genomic DNA from 12 individuals from Long Key Florida was used by GenoScreen for microsatellite development. The DNA quantity was assessed using the Picogreen assay (Invitrogen). To improve polymorphism detection the DNA from 12 individuals were pooled equimolarly. Microsatellite libraries were developed using $1 \mu \mathrm{g}$ of pooled DNA and 454 GS FLX Titanium pyrosequencing of the enriched DNA (Malausa et al., 2011). Briefly, total DNA was

47 enriched for microsatellite loci using 8 probes (AG, AC, AAC, AAG, AGG, ACG, ACAT and 48 ATCT) and subsequently amplified. The PCR products were purified, quantified, and GS FLX 49 libraries were developed following the manufacturer's protocols (Roche Diagnostics) and 50 sequenced on a GS FLX-PTP. The level of coverage used to develop microsatellite loci was 1/32 
51 of a plate. This technique allowed the identification of 12676 potential microsatellite primers.

52 The bioinformatics program QDD was used (Meglécz et al., 2010) to identify sequences that

53 were optimal for primer design and validated 737 pairs of primers. Tri-repeats and tetra-repeats

54 were favored in order to minimize stutter bands and increase the probability of accurate allele

55 scoring. The following selection parameters were used to design microsatellite primers:

56 minimum melting temperature $\left(\mathrm{T}_{\mathrm{m}}\right)$ of $60^{\circ} \mathrm{C}$; optimum $\mathrm{T}_{\mathrm{m}}$ of $71^{\circ} \mathrm{C}$; maximum difference in $\mathrm{T}_{\mathrm{m}}$

57 between primer pairs of $5^{\circ} \mathrm{C}$; and primer length of 20-30bp. Twenty-four validated sets of $P$.

58 guttatus primers and 29 sets of previously designed microsatellite primers for $P$. argus (Diniz et

59 al., 2004; 2005; Tringali et al., 2008) were tested for amplification. Primer sets were discarded if

60 they either failed to amplify or amplified three or more distinct fragments. The 13 microsatellites

61 developed by Genoscreen and 2 microsatellites previously developed (Tringali et al., 2008) for

62 P. argus were tested for polymorphism in P. guttatus using the forward labeled fluorescent

63 primers 6-FAM, HEX, NED, and PET. Twelve of the thirteen microsatellites identified by

64 Genoscreen were partitioned into 3 multiplexes consisting of 4 primer pairs. The forth multiplex

65 consisted of a Genoscreen primer pair and the two primer pairs developed for P. argus (Tringali

66 et al., 2008). A unique fluorescent label was attached to the forward primers of each multiplex.

67 Annealing temperatures for all primer pairs were calculated with Multiplex Manager (Holleley \&

68 Geerts, 2009) using 200 nanomolar primer concentration and $10^{\circ} \mathrm{C}$ below the primer melting

69 temperature Tm.

70 Each multiplex PCR was performed with a Veriti thermal cycler (Applied Biosystems).

71 Our protocol followed the manufacturer's recommendations (Qiagen Microsatellite Multiplex

72 PCR Kit), however, we initially compared reaction volumes of $25 \mu 1,10 \mu 1$ and $5 \mu 1$ for each

73 multiplex in 24 individuals. Results were identical for each reaction volume, therefore to reduce 
74 costs the total volume of the PCR reaction was scaled down from $25 \mu 1$ to $5 \mu 1$ whilst keeping the

75 concentrations of all PCR reagents the same. The PCR reaction mix consisted of $0.5 \mu 1$ of the

$7610 \mathrm{X}$ primer mix $(1 \mu \mathrm{M}$ primer $+1 \mu \mathrm{M}$ fluorescent primer), $2.5 \mu 1$ of Type-it Multiplex PCR

77 Master Mix (Qiagen), $1 \mu \mathrm{l}$ of molecular grade water and $1 \mu 1$ of $(10-20 \mathrm{ng} / \mu \mathrm{l})$ genomic DNA.

78 The PCR conditions consisted of an initial denaturation at $95{ }^{\circ} \mathrm{C}$ for $5 \mathrm{~min}$, followed by 26

79 cycles at $95{ }^{\circ} \mathrm{C}$ for $30 \mathrm{~s}, 59-65^{\circ} \mathrm{C}$ for $120 \mathrm{~s}$ (the lowest primer annealing temperature was

80 chosen for each multiplex; Multiplex $1=58{ }^{\circ} \mathrm{C}$, Multiplex $2=62{ }^{\circ} \mathrm{C}$, Multiplex $3=60{ }^{\circ} \mathrm{C}$,

81 Multiplex $4=65^{\circ} \mathrm{C}$ ), and $72{ }^{\circ} \mathrm{C}$ for $30 \mathrm{~s}$. This was followed by final extension at $60{ }^{\circ} \mathrm{C}$ for 30

$82 \mathrm{~min}$. To facilitate the fragment analysis, PCR products were diluted 1:1 with $5 \mu 1 \mathrm{MQ}$ water.

83 From the diluted product, $0.5 \mu 1$ was mixed with $9.5 \mu 1$ of a mix consisting of Hi-Di Formamide ${ }^{\circledR}$

84 (Applied Biosystems) and GeneScan - 500 LIZ Size Standard (37:1) in a 96 well PCR plate.

85 Fragment analysis was performed on an ABI 3730xl automatic DNA sequencer (Applied

86 Biosystems, USA) at the University of Manchester DNA Sequencing Facility. Microsatellite

87 alleles were scored using the GeneMapper ${ }^{\circledR}$ v3.7 software package (Applied Biosystems).

88 Binning of microsatellite alleles and error checking were preformed using the R package

89 MsatAllele version 1.02 (Alberto, 2009) and R statistical software v2.15.1 (Ihaka \& Gentleman,

90 1996). The entire data set was checked for variability and departures from Hardy-Weinberg

91 equilibrium (HWE) and the fixation index (FIS) was calculated using the software package

92 Genodive v2.0b23 (Meirmans \& Van Tienderen, 2004; Meirmans, 2012). The Benjamini

93 Hochberg method (i.e. the false discovery rate) was used to correct for multiple comparisons of

94 HWE (Benjamini \& Hochberg, 1995). Linkage disequilibrium between loci was tested using

95 Genepop on the Web v4.2 (Raymond \& Rousset, 1995; Rousset, 2008). Markov chain

96 parameters for Genepop were set to the following: dememorization number $10 \mathrm{~K}$, number of 
97 batches $1 \mathrm{~K}$, and number of iterations per batch $10 \mathrm{~K}$. Null allele frequencies and scoring errors

98 caused by stutter peaks or large allele dropout was calculated with MICROCHECKER (Van

99 Oosterhout et al., 2004).

100 Results

101 Six out of 13 microsatellites developed by Genoscreen were found to be either

102 monomorphic or too difficult to score and were removed from the analysis. Twenty-seven out of

10329 P. argus microsatellites failed to produce PCR products. One out of the two P. argus

104 microsatellites that did produce a PCR product was too difficult to score and was removed from

105 the analysis. Table 1 summarizes the characteristics of the eight primer pairs of polymorphic and

106 easy to score microsatellite loci developed for the spotted spiny lobster $P$. guttatus. No evidence

107 of linkage disequilibrium was found among any of these loci. We were unable to test for

108 Mendelian inheritance since crossbreeding of $P$. guttatus has yet to be achieved under laboratory

109 conditions.

110 Samples from Long Key Florida $(\mathrm{N}=24)$ and Bermuda $(\mathrm{N}=33)$ were genotyped using

111 the eight developed primers. The number of alleles ranged from 8 to 20 per locus. Significant

112 deviations from Hardy-Weinberg equilibrium were found in one locus from Florida and three

113 loci from Bermuda (Table 2). These deficiencies could be due to null alleles or the Wahlund

114 effect (Johnson \& Black, 1984). The latter is possible considering the potential for extensive

115 geneflow in this species. However, null alleles are a common characteristic of the microsatellites

116 of many marine invertebrates, so could also be responsible for the deviations from HWE

117 (Dailianis et al., 2011). Indeed null alleles were detected by MICROCHECKER in the four loci

118 that deviated from HWE (Par-Fwc05, PG3, PG21, PG22). Null allele frequencies in these loci

119 ranged from $20 \%$ to $22 \%$ (Table 1). Although null alleles have been found to inflate levels of 
120 population structure, they do not create population structure where it does not already exist

121 (Chapuis \& Estoup, 2007; Carlsson, 2008).

\section{Discussion}

123

Population genetics studies have yet to be conducted on this coral reef lobster species that

124 is facing increasing fishing pressure. Even though 4 microsatellite primers show evidence of null

125 alleles, the moderate null allele frequencies and number of alleles suggests these eight primers

126 are useful for conducting future genetic studies of $P$. guttatus. This research can be used to help

127 develop conservation and fishery management plans for this understudied species.

\section{Acknowledgements}

We thank Dr. Tammy Trott from the Bermuda Fisheries Department for providing samples for this study and Josh Anderson, Jason Spadero, and Mike Dixon for helping to collect samples in the Florida Keys. We are grateful to Antoine Destombes at Genoscreen for his help

132 with this project.

\section{References}

Acosta CA, Robertson D 2003. Comparative spatial ecology of fished spiny lobsters Panulirus argus and an unfished congener $P$. guttatus in an isolated marine reserve at Glover's Reef atoll, Belize. Coral Reefs 22:1-9.

Alberto F 2009. MsatAllele_1.0: An R Package to Visualize the Binning of Microsatellite Alleles. Journal of Heredity 100:394-397.

Ben-Horin T, Iacchei M, Selkoe KA, Mai TT, Toonen RJ 2009. Characterization of eight polymorphic microsatellite loci for the California spiny lobster, Panulirus interruptus and cross-amplification in other achelate lobsters. Conservation Genetics Resources 1:193-197.

Benjamini Y, Hochberg Y 1995. Controlling the false discovery rate: a practical and powerful approach to multiple testing. Journal of the Royal Statistical Society. Series B (Methodological) 57:289-300.

149 Chapuis MP, Estoup A 2007. Microsatellite Null Alleles and Estimation of Population 
150

151

152

153

154

155

156

157

158

159

160

161

162

163

164

165

166

167

168

169

170

171

172

173

174

175

176

177

178

179

180

181

182

183

184

185

186

187

188

189

190

191

192

193

194

195

Differentiation. Molecular Biology and Evolution 24:621-631.

Dailianis T, Tsigenopoulos CS, Dounas C, Voultsiadou E 2011. Genetic diversity of the imperilled bath sponge Spongia officinalis Linnaeus, 1759 across the Mediterranean Sea: patterns of population differentiation and implications for taxonomy and conservation. Molecular Ecology 20:3757-3772.

Dao HT, Todd EV, Jerry DR 2013. Characterization of polymorphic microsatellite loci for the spiny lobster Panulirus spp. and their utility to be applied to other Panulirus lobsters. Conservation Genetics Resources 5:43-46-46.

Diniz FM, Maclean N, Ogawa M, Paterson IG, Bentzen P 2005. Microsatellites in the overexploited spiny lobster, Panulirus argus: Isolation, characterization of loci and potential for intraspecific variability studies. Conservation Genetics 6:637-641.

Diniz FM, Maclean N, Paterson IG, Bentzen P 2004. Polymorphic tetranucleotide microsatellite markers in the Caribbean spiny lobster, Panulirus argus. Molecular Ecology Notes 4:327329.

Fanning L, Mahon R, McConney P 2011. Towards marine ecosystem-based management in the wider Caribbean. In: Jentoft S, Bavinck M eds. Amsterdam University Press, 157-175.

Holleley C, Geerts P 2009. Multiplex Manager 1.0: a cross-platform computer program that plans and optimizes multiplex PCR. Biotechniques 46:511-517.

Ihaka R, Gentleman R 1996. R: A Language for Data Analysis and Graphics. Journal of Computational and Graphical Statistics 5:299-314.

Johnson MS, Black R 1984. The Wahlund effect and the geographical scale of variation in the intertidal limpet Siphonaria sp. Marine Biology 79:295-302.

Kennington WJ, Levy E, Berry O, Groth DM, Waite AM, Johnson MS, Melville-Smith R 2010. Characterization of 18 polymorphic microsatellite loci for the western rock lobster Panulirus cygnus. Conservation Genetics Resources 2:389-391-391.

Liu L, Yang X, Liu C 2013. Eleven novel polymorphic microsatellite loci in the ornate spiny lobster Panulirus ornatus (Decapoda: Palinuridae). Journal of genetics 92:e65-7.

Malausa T, Gilles A, Meglécz E, Blanquart H, Duthoy S, Costedoat C, Dubut V, Pech N, Castagnone-Sereno P, Délye C et al. 2011. High-throughput microsatellite isolation through 454 GS-FLX Titanium pyrosequencing of enriched DNA libraries. Molecular Ecology Resources 11:638-644.

Meglécz E, Costedoat C, Dubut V, Gilles A, Malausa T, Pech N, Martin J-F 2010. QDD: a userfriendly program to select microsatellite markers and design primers from large sequencing projects. Bioinformatics 26:403-404.

Meirmans PG 2012. AMOVA-Based Clustering of Population Genetic Data. Journal of Heredity 103:744-750.

Meirmans PG, Van Tienderen PH 2004. genotype and genodive: two programs for the analysis of genetic diversity of asexual organisms. Molecular Ecology Notes 4:792-794.

Ptacek MB, Sarver SK, Childress MJ, Herrnkind WF 2001. Molecular phylogeny of the spiny lobster genus Panulirus (Decapoda: Palinuridae). Marine and Freshwater Research 52:1037.

Raymond M, Rousset F 1995. Genepop (version 1.2): Population genetics software for exact tests and ecumenicism. Journal of Heredity 86:248-249.

Rousset F 2008. Genepop'007: a complete re-implementation of the Genepop software for windows and linux. Molecular Ecology Resources 8:103-106.

Sharp WC, Hunt JH, Lyons WG 1997. Life history of the spotted spiny lobster, Panulirus guttatus, an obligate reef-dweller. Marine and Freshwater Research 48:687-698. 
196 Tringali MD, Seyoum S, Schmitt SL 2008. Ten di- and trinucleotide microsatellite loci in the 197 Caribbean spiny lobster, Panulirus argus, for studies of regional population connectivity. 198 Molecular Ecology Resources 8:650-652.

199 Van Oosterhout C, Hutchinson WF, Wills DPM, Shipley P 2004. MICRO-CHECKER: software 200 for identifying and correcting genotyping errors in microsatellite data. Molecular Ecology $201 \quad$ Notes 4:535-538.

202 Wynne SP, Coté IM 2007. Effects of habitat quality and fishing on Caribbean spotted spiny 203 204 lobster populations. Journal of Applied Ecology 44:488-494. 


\section{Table $\mathbf{1}$ (on next page)}

\section{Revised Table 1}

Table 1 Characterization of eight microsatellite loci for Panulirus guttatus with GenBank (GenBank Accession Number), $\mathrm{T}_{\mathrm{A}}$ (annealing temperature), Na (number of alleles), Ho (observed heterozygosity), He (expected heterozygosity), Fis (fixation index), $P$ ( $P$-value for deviation from Hardy-Weinberg equilibrium), and $F_{N A}$ (null allele frequency). Fluorescent labels on forward primers and significant values after the false discovery rate correction for multiple comparisons (Benjamini \& Hochberg, 1995) are in bold. 
2 Table 1 Characterization of eight microsatellite loci for Panulirus guttatus with GenBank (GenBank Accession Number),

$3 \mathrm{~T}_{\mathrm{A}}$ (annealing temperature), $\mathrm{Na}$ (number of alleles), Ho (observed heterozygosity), He (expected heterozygosity), Fis

4 (fixation index), $P$ ( $P$-value for deviation from Hardy-Weinberg equilibrium), and $\mathrm{F}_{\mathrm{NA}}$ (null allele frequency). Fluorescent

5 labels on forward primers and significant values after the false discovery rate correction for multiple comparisons

6 (Benjamini \& Hochberg, 1995) are in bold.

7

\begin{tabular}{|c|c|c|c|c|c|c|c|c|c|c|c|c|c|c|c|c|c|c|}
\hline \multirow[t]{2}{*}{ Locus } & \multirow[t]{2}{*}{ Primer sequence (5' to 3') } & \multirow[t]{2}{*}{ Multiplex } & \multirow[t]{2}{*}{$\begin{array}{l}\text { GenBank } \\
\text { Gen }\end{array}$} & \multirow[t]{2}{*}{ Repeat Motif } & \multirow[t]{2}{*}{ Range (bp) } & \multirow[t]{2}{*}{$\overline{T_{A}}$} & \multicolumn{3}{|c|}{ Florida $(N=24)$} & \multirow[b]{2}{*}{ Fis } & \multirow[b]{2}{*}{$P$} & \multirow[b]{2}{*}{$\mathbf{F}_{\mathrm{NA}}$} & \multicolumn{4}{|c|}{ Bermuda ( $\mathrm{N}=\mathbf{3 3}$ ) } & \multirow[b]{2}{*}{$P$} & \multirow[b]{2}{*}{$\overline{\mathbf{F}_{\mathrm{NA}}}$} \\
\hline & & & & & & & $\mathrm{Na}$ & Ho & $\mathrm{He}$ & & & & $\mathbf{N a}$ & Ho & $\mathrm{He}$ & Fis & & \\
\hline \multirow[t]{2}{*}{$\begin{array}{c}\text { Pgut-3 } \\
\end{array}$} & F: GCTGGAGAGGGAGGAACTGT-6FAM & 1 & KC800822 & $(\mathrm{GAG}) 12$ & $95-131$ & 66.7 & 16 & 0.696 & 0.843 & 0.175 & 0.088 & --- & 11 & 0.667 & $\overline{0.892}$ & $\overline{0.253}$ & $<0.001$ & 0.141 \\
\hline & R: CCCTTCCTCATCTTTCTTCTCC & & & & & $\overline{63.3}$ & & & & & & & & & & & & \\
\hline \multirow[t]{2}{*}{$\begin{array}{ll}\text { Pgut-6 } \\
\end{array}$} & F: CCCATTCATTTTCGTCATCA-PET & 1 & KC800823 & (ATC)12 & $140-165$ & 58.3 & 11 & 0.75 & 0.872 & 0.139 & 0.208 & --- & 10 & 0.710 & 0.855 & 0.170 & 0.589 & --- \\
\hline & R: CCTTGATTTCAAATTGCTGC & & & & & 59.4 & & & & & & & & & & & & \\
\hline \multirow[t]{2}{*}{$\begin{array}{l}\text { Pgut-9 } \\
\end{array}$} & F: GTGTGGTTGTTGACGTTGCT-VIC & 2 & KC800824 & (TGT)17 & $78-119$ & 64.6 & 8 & 0.667 & 0.834 & 0.201 & 0.06 & --- & 11 & 0.938 & 0.758 & 0.236 & 0.727 & $\overline{---}$ \\
\hline & R: GACTCGAAGACGCAGACGTA & & & & & 63.5 & & & & & & & & & & & & \\
\hline \multirow[t]{2}{*}{$\overline{\text { Pgut-15 }}$} & F: CACCAGTTGTGAAAATACTTTTGCT-PET & 2 & KC800825 & (GATA)6 & $133-178$ & 63.3 & 13 & 0.958 & 0.836 & 0.146 & 0.365 & --- & 12 & 0.844 & 0.856 & 0.014 & 0.142 & ---- \\
\hline & R: GTCCTAGAAAAGATAAAAGCTTAGGGA & & & & & $\overline{62.4}$ & & & & & & & & & & & & \\
\hline \multirow[t]{2}{*}{$\begin{array}{l}\text { Pgut-21 } \\
\end{array}$} & F: TGCCCTTGGCAAAATCTCTA-VIC & 3 & KC800826 & $\begin{array}{l}(\mathrm{TCTA}) 8 \\
\end{array}$ & $167-224$ & 60.6 & 9 & 0.875 & $\overline{0.829}$ & $\overline{0.055}$ & $\overline{0.711}$ & $\overline{---}$ & 12 & 0.697 & 0.823 & 0.153 & $<0.001$ & 0.204 \\
\hline & R: GCGAACTGAACGCTTCCTAA & & & & & 62.7 & & & & & & & & & & & & \\
\hline \multirow[t]{2}{*}{ Pgut-22 } & F: CCTTGCATCCCAGACGTGTA-6FAM & 3 & KC800827 & (TGTA) 10 & $74-115$ & 64.3 & 11 & 0.5 & 0.839 & $\overline{0.404}$ & 0.129 & --- & 9 & 0.5 & 0.837 & 0.403 & $<0.001$ & 0.217 \\
\hline & R: ACGCGGACACATACTCTCCT & & & & & 65.7 & & & & & & & & & & & & \\
\hline \multirow[t]{2}{*}{\begin{tabular}{|l|l} 
Pgut-23 \\
\end{tabular}} & F: AAGGAAATAGCCTCGCCAAT-NED & 3 & KC800828 & (AGAT)11 & $133-171$ & 62.5 & 10 & 0.409 & 0.844 & 0.515 & $<0.001$ & 0.22 & 8 & 0.613 & 0.765 & 0.199 & 0.366 & --- \\
\hline & R: AATGGGTACCTGGCTCAAGA & & & & & 62.9 & & & & & & & & & & & & \\
\hline \multirow[t]{2}{*}{ Par-Fwc05 } & F: AGAGAGACGCTGCTGTTCTTC-6FAM & 4 & EF620542 & (CA) $18 \mathrm{C}(\mathrm{CA}) 10$ & $131-179$ & 65.1 & 8 & 0.583 & 0.753 & 0.226 & 0.041 & --- & 20 & 0.781 & 0.919 & 0.150 & 0.041 & --- \\
\hline & R: AAAGGGCATCCTCGGTAGAGTC & & & & & 66.7 & & & & & & & & & & & & \\
\hline
\end{tabular}

